Article

\title{
The Antecedents and Consequences of Health Literacy in an Ecological Perspective: Results from an Experimental Analysis
}

\author{
Chiara Lorini ${ }^{1, *}$, Francesca Ierardi ${ }^{2}$ (1) , Letizia Bachini ${ }^{2}$, Martina Donzellini ${ }^{3}$, Fabrizio Gemmi ${ }^{2}$ \\ and Guglielmo Bonaccorsi ${ }^{1}$ \\ 1 Department of Health Science, University of Florence, Viale GB Morgagni 48, 50134 Firenze, Italy; \\ guglielmo.bonaccorsi@unifi.it \\ 2 Quality and Equity Unit, Regional Health Agency of Tuscany, 50141 Florence, Italy; \\ francesca.ierardi@ars.toscana.it (F.I.); letizia.bachini@ars.toscana.it (L.B.); \\ fabrizio.gemmi@ars.toscana.it (F.G.) \\ 3 School of Specialization in Hygiene and Preventive Medicine, University of Florence, 50134 Florence, Italy; \\ martinadonzellini@gmail.com \\ * Correspondence: chiara.lorini@unifi.it; Tel.: +39-055-275-1065; Fax: +39-055-275-1093 (ext. 50134)
}

Received: 13 March 2018; Accepted: 16 April 2018; Published: 19 April 2018

check for updates

\begin{abstract}
This study analyses the relationship between the antecedents and consequences of health literacy (HL) at the ecological level among the nations involved in the European Health Literacy Survey (HLS-EU). The antecedents and consequences were investigated by means of proxy indicators. The HL was measured using the 47-item HLS-EU questionnaire (HLS-EUQ47) and the Newest Vital Sign (NVS). The two measures stood in significant correlation to the outcomes of the sub-discipline of the Euro Health Consumer Index ( $r=0.790$ for HLS-EUQ47; $r=0.789$ for NVS). The HLS-EUQ47 also stood in correlation to the percentage of population with post-secondary education $(r=0.810)$, the reading performance for 15-year-old students $(r=0.905)$, the presence of a national screening program for breast $(r=0.732)$ or cervical cancer $(r=0.873)$. The NVS stood in correlation with the unemployment rate $(r=-0.778)$, the Gross Domestic Product $(r=0.719)$, the Gini coefficient $(r=-0.743)$, the rank of the Euro Patient Empowerment Index $(r=-0.826)$, the expenditure on social protection $(r=0.814)$, the Consumer Empowerment Index $(r=0.898)$, the percentage of adults using the internet for seeking health information $(r=0.759)$, the prevalence of overweight individuals $(\mathrm{r}=-0.843)$, the health expenditure $(\mathrm{r}=0.766)$, as well as the percentage of individuals using the internet for interacting with public authorities $(\mathrm{r}=0.755)$. This study provides some preliminary considerations regarding alternative means by which to study HL and proposes new methods for experimentation. The methods and the results could offer a means by which the relationship between society and overall healthcare protection could be strengthened.
\end{abstract}

Keywords: health literacy; ecological study; antecedents; consequences; determinants of health

\section{Introduction}

Health literacy (HL) is a multifaceted concept that concerns the capacities of individuals to meet the complex demands of health in a modern society [1].

With regard to research and practice in terms of HL, two approaches have predominated during recent decades: the individual (clinical) level and the public health level. The first approach is the oldest: it focuses on an individual's capacity to obtain, process, and understand basic health information, including health services, needed to make appropriate health-related decisions. This approach highlights existing gaps within strategies of treatment, prevention, and health promotion as well as 
overall health behavior, including specific individual health-related outcomes [2]. The second approach incorporates knowledge as to the social determinants of health and relates to the definition of public health literacy, "the degree to which individuals and groups can obtain, process, understand, evaluate, and act upon information needed to make public health decisions that benefit the community" [3,4].

In terms of the public health perspective, Sørensen et al. [5] proposed a comprehensive model with an integrated definition: "Health literacy is linked to literacy and entails people's knowledge, motivation and competences to access, understand, appraise, and apply health information in order to make judgments and take decisions in everyday life concerning healthcare, disease prevention and health promotion to maintain or improve quality of life during the life course". The conceptual framework proposed by Sørensen identified four dimensions of HL (access, understand, process, and apply) which could be applied to three domains (health care, disease prevention, health promotion). The framework also took into consideration the proximal and distal factors (antecedents) which impact HL as well as its related outcomes (consequences). Within Sørensen's framework, antecedents specifically refer to societal and environmental factors (i.e., demographics, culture, language, political forces, societal systems) as distal factors whereas situational determinants (i.e., social support, family and peer influence, media use, physical environment) and personal determinants (i.e., age, gender, race, socioeconomic status, education, occupation, employment, income, literacy) are considered proximal factors. Consequences at both the individual and population level refer to health service use and health costs; health behaviour and health outcomes; participation and empowerment in health issues; equity and sustainability of public health issues. Such a framework suggests two levels of analysis and intervention, the subject level and the ecological level. Sørensen's model has been used as a basis for developing the multidimensional questionnaire used to measure and compare HL in the general population (the HLS-EU-Q) of eight European countries in the European Health Literacy Survey (HLS-EU) [6,7]. To date, it has been the first attempt to measure HL in different countries at the same time using the same measures.

Many studies have shown the correlation between antecedents and HL, as well as between consequences and HL [8-11]. The majority of such studies focused on only a few similar or correlating factors; this has led to a fragmentation of the results without an overall quantitative assessment of the relationship among all relevant factors.

To the best of our knowledge, no studies have been published regarding the ecological relationships between HL and its antecedents and consequences in terms of macro-level factors. Such information could guide policy makers in providing appropriate responses to the needs of citizens. As such, this study identifies a set of indicators, available using free data from international databases or from published documents, to test according to an ecological model. Accordingly, this paper provides a novel approach to the study of health literacy. This paper aims to advance our understanding of the relationship among nationally determined contextual characteristics within the countries included in the HLS-EU in terms of their role as HL antecedents or consequences.

\section{Materials and Methods}

The study objective was addressed using an ecological model in which the antecedents and consequences of HL were measured at country level. The design of the study was suitable to investigate macro-level properties, namely political, economic, demographic, and health contexts, through proxy indicators.

\subsection{HL (Health Literac) Measurements}

Data on HL were obtained through consultation of the published results of the first HLS-EU, conducted in 2011 in eight countries (Austria, Bulgaria, Germany, Greece, Ireland, the Netherlands, Poland, and Spain) $[7,12,13]$. In this survey, HL was measured by means of two tools: the HLS-EUQ47 and the Newest Vital Sign (NVS). The first consisted of 47 items comprising the core of the HL model, a twelve-cell matrix positing the key processes of accessing, understanding, appraising, and 
applying health-related information within three domains (healthcare, disease prevention, health promotion) [5,6]. According to Nutbeam's definition [14], it assessed functional, interactive, and critical HL (Table 1).

Table 1. Health literacy (HL) definition, according to Nutbeam [14].

\begin{tabular}{cl}
\hline Functional HL & \multicolumn{1}{c}{ Basic Reading, Writing, and Literacy Skills } \\
\hline Interactive HL & $\begin{array}{l}\text { Communicative and social skills that can be used to derive meaning } \\
\text { from different forms of communication, and to apply new information } \\
\text { to changing circumstances }\end{array}$ \\
\hline Critical HL & $\begin{array}{l}\text { Cognitive and social skills required to critically analyse information, } \\
\text { and to use this information to exert greater control over life events and } \\
\text { situations through individual and collective action to address the social, } \\
\text { economic and environmental determinants of health }\end{array}$ \\
\hline
\end{tabular}

For each item, respondents rated the perceived difficulty of a given task, resulting in a subjective assessment of HL. The answers were placed on a four-category Likert scale (from "very easy" to "very difficult") then converted into a score. Using the scores of the 47 items, the authors constructed a comprehensive general index of HL (total score ranging from 0 to 50) which was used to define the ranges for different levels of HL ("inadequate", "problematic", "sufficient", "excellent" general-HL).

The NVS is a rapid assessment instrument for measuring functional HL, including numeracy. It assesses the respondents' ability to read and apply information from a nutritional label for ice cream and constitutes an objective assessment of HL [15]. The UK version of the NVS [16], which was used in the HLS-EU, consisted of seven questions related to the nutritional label. According to the number of correct answers (from 0 to 6), a raw score was computed indicating the likelihood of a level of HL ("high likelihood of limited literacy", "possibility of limited literacy", "high likeliness of adequate literacy").

Literature data $[7,13]$ report both the descriptive statistics of the total score and the levels of HLS-EU-Q47 and of NVS by country; however, for this study, only mean values of HLS-EU-Q47 and of NVS were considered.

\subsection{Antecedents and Consequences of $H L$}

The final set of antecedents and outcome indicators was identified following a three-stage approach. First, Sørensen review [5] was used to define antecedents and consequences by area. Then, a literature review was conducted to select a list of indicators related to antecedents and consequences according to the different areas. Finally, the availability of the listed indicators for the eight countries involved in the HLS-EU was verified via international databases and documents.

The literature review was conducted through a Pubmed search of ecological studies conducted at the national level, including studies which analysed any aspect of health. Moreover, web-available documents issued by international organizations focused on international comparisons describing health or health-related indicators at the national level were searched and reviewed. Selected documents were analyzed to identify all indicators used and a list of these indicators was compiled.

Subsequently, the availability of each of the listed indicators was checked. Aggregate country-level antecedent and consequence indicator data were extracted from several databases and/or documents which was available from the websites of Eurostat, European Health for All (HFA-DB), the Organisation for Economic Co-operation and Development (OECD), the Health Consumer Powerhouse (HCP), the World Health Organization, and the European Commission. To obtain the most reliable information for comparison with the HL average, data was considered adequate and included in analysis if it referred to the three-year period preceding the HLS-EU (2009-2011). When data were available which referred to more than one year within the three-year period, those relating to the year closest to the HLS-EU were included in the analysis. Finally, indicators were included in the analysis only when 
available for each of the eight countries included in the HLS-EU. If an area was over-represented in the final database (i.e., with more than five indicators), the less frequently used indicators for international comparison were omitted.

\subsection{Statistical Analysis}

Using each country as a unit of analysis, a correlation analysis was performed by means of Spearman rank correlation coefficients, which included the final set of indicators and the HL measures (HLS-EU-Q47 and NVS mean scores).

The analysis was conducted using STATA, release 12.1 (StataCorp LLC, College Station, TX, USA). Statistical significance was set at $p=0.05$.

\section{Results}

\subsection{The Selection of the List of Indicators}

According to Sørensen's review, he antecedents and consequences by areas are listed in Table 2. Since health outcomes could be considered both antecedents and consequences of HL, this area was included in both sections.

Table 2. Conceptual models of the areas for antecedents (A) and consequences (B) of health literacy, developed from the results of Sørensen's review [5].

\begin{tabular}{|c|c|c|}
\hline Levels & Areas & Sub-Areas \\
\hline \multirow[t]{5}{*}{$\begin{array}{l}\text { Personal Determinants } \\
\text { (Proximal Factors) }\end{array}$} & Demographic & $\begin{array}{l}\text { Age } \\
\text { Gender } \\
\text { Race/ethnicity }\end{array}$ \\
\hline & Competences & $\begin{array}{l}\text { Literacy } \\
\text { Education level } \\
\text { Operational competences } \\
\text { Interactive competences } \\
\text { Autonomous competences } \\
\text { Informational competences } \\
\text { Contextual competences } \\
\text { Cultural competences } \\
\text { Media use } \\
\text { Peer and parent influences } \\
\text { Reading and arithmetical skills }\end{array}$ \\
\hline & Socioeconomic & $\begin{array}{l}\text { Occupation } \\
\text { Employment status } \\
\text { Income } \\
\text { Income discrepancy }\end{array}$ \\
\hline & Health & $\begin{array}{l}\text { Disease severity } \\
\text { Health status } \\
\text { Health-related experience } \\
\text { Personal competences such as vision, hearing, } \\
\text { verbal ability, memory and reasoning } \\
\text { Cognitive abilities } \\
\text { Physical abilities }\end{array}$ \\
\hline & Healthcare & $\begin{array}{l}\text { Health coverage } \\
\text { Health system } \\
\text { Communication and assessment skills of people } \\
\text { with whom individuals interact for health } \\
\text { Complexity and difficulty of the printed and } \\
\text { spoken messages in the healthcare environment }\end{array}$ \\
\hline $\begin{array}{l}\text { Situational Determinants } \\
\text { (Distal Factors) }\end{array}$ & Policy & $\begin{array}{l}\text { Health promotion actions (education, social } \\
\text { mobilization, advocacy) } \\
\text { Ability of the media, the marketplace, and } \\
\text { governmental agencies to provide health } \\
\text { information in an appropriate manner } \\
\text { Social support } \\
\text { Education system } \\
\text { Social, environmental and political forces }\end{array}$ \\
\hline
\end{tabular}


Table 2. Cont.

\begin{tabular}{|c|c|c|}
\hline Levels & Areas & Sub-Areas \\
\hline \multirow[t]{6}{*}{ Individual } & Health outcomes & $\begin{array}{l}\text { Health status (also self-reported) } \\
\text { Health outcome }\end{array}$ \\
\hline & Health behavior & $\begin{array}{l}\text { Health behaviors } \\
\text { Prevention behaviors } \\
\text { Health-promoting behaviors } \\
\text { Screening behaviors } \\
\text { Compliance } \\
\text { Medical or medication treatment errors }\end{array}$ \\
\hline & Empowerment & $\begin{array}{l}\text { Attitudes } \\
\text { Self-efficacy } \\
\text { Capacity to act independently on knowledge } \\
\text { Motivation and self-confidence } \\
\text { Individual resilience } \\
\text { Ability to apply information to novel situations } \\
\text { Self-management skills/ability to care } \\
\text { Health knowledge (risk, diseases and } \\
\text { treatments) } \\
\text { Improved capacity to influence social norms } \\
\text { and interact with social groups } \\
\text { Improved capacity to act on social and } \\
\text { economic determinants of health }\end{array}$ \\
\hline & Participation & $\begin{array}{l}\text { Ability to participate in public and private } \\
\text { dialogues about health, medicine, scientific } \\
\text { knowledge and cultural beliefs } \\
\text { Patients-provider interactions } \\
\text { Screening behaviors }\end{array}$ \\
\hline & Health services use & $\begin{array}{l}\text { Hospitalization } \\
\text { Emergency care } \\
\text { Use of healthcare services } \\
\text { Healthcare access }\end{array}$ \\
\hline & Sustainability & $\begin{array}{l}\text { Social injustice } \\
\text { Healthcare costs }\end{array}$ \\
\hline Community/Social & Equity & $\begin{array}{l}\text { Healthcare access } \\
\text { Improved capacity to influence social norms } \\
\text { and interact with social groups } \\
\text { Improved capacity to act on social and } \\
\text { economic determinants of health } \\
\text { Social injustice }\end{array}$ \\
\hline
\end{tabular}

Literature review led to the selection of eight ecological studies [17-24] and 14 documents [25-38], generating a list of approximately 250 indicators (Table S1). As shown in Table 1, some areas were not represented by any indicator since they were not investigated in the selected studies. Most of the indicator data were not available in the consulted databases or documents for every county included in the HLS-EU in the period 2009-2011.

The final list of indicators $(N=37)$ included in the analysis as well as the data sources is reported in Table 3. Table S2 contains the final dataset.

\subsection{The Correlation Analysis}

The HLS-EUQ47 and the NVS mean scores are not significantly correlated $(r=0.419 ; p=0.301)$. Table 4 reports the results of the correlation analysis. The HLS-EUQ47 and the NVS scores present different results. With regard to antecedents, the HLS-EUQ47 mean score stood in significant correlation to the percentage of population with post-secondary education $(r=0.810)$, reading performance for 15-year-old students $(r=0.905)$, the presence of a national breast cancer screening program $(r=0.732)$, and the presence of a national cervical cancer screening program $(r=0.873)$. Regarding consequences, the mean score stood in significant correlation to only the "outcomes" sub-discipline of the Euro Health Consumer Index $(r=0.790)$. 
Table 3. Indicators included in the correlation analysis and data sources.

\begin{tabular}{|c|c|c|c|}
\hline Sub-Area & Indicator & Data Source & Year \\
\hline \multicolumn{4}{|c|}{ Antecedents } \\
\hline Gender & Women/100 men & Eurostat & 2011 \\
\hline Age & Population aged $65+(\%)$ & Health for All & 2011 \\
\hline Race/ethnicity & Foreign-born population $(\%)$ & & 2011 \\
\hline Education level & Population with post-secondary education aged $25+(\%)$ & Health for All & 2010 \\
\hline Education level & $\begin{array}{l}\text { Lifelong learning-\% persons aged } 25 \text { to } 64 \text { who stated that they received } \\
\text { education or training in the four weeks preceding the survey }\end{array}$ & OECD & 2011 \\
\hline Media use & Population that use the Internet at least ones a week (\% of individuals) & Eurostat & 2010 \\
\hline Reading and arithmetical skills & Reading achievement (average reading performance for 15 -year-old students) & OECD & 2009 \\
\hline Employment status & Unemployment rate $(\%)$ & Health for All & 2011 \\
\hline Income & Gross Domestic Product (GDP), U.S.\$ per capita & Health for All & 2011 \\
\hline Income discrepancy & Gini coefficient & Health for All & 2011 \\
\hline Health status & Prevalence of chronic depression (\%) & OECD & 2011 \\
\hline cognitive abilities & Prevalence of dementia (\%) & OECD & 2009 \\
\hline Health coverage & National breast cancer screening program (0 if not, 1 if yes) & $\begin{array}{l}\text { European } \\
\text { Commission }\end{array}$ & 2011 \\
\hline Health coverage & National cervical cancer screening program ( 0 if not, 1 if yes) & $\begin{array}{l}\text { European } \\
\text { Commission }\end{array}$ & 2011 \\
\hline Health systems & Hospitals per 100,000 abitants & Health for All & 2011 \\
\hline Health systems & Euro Patient Empowerment Index-total score-rank & $\mathrm{HCP}$ & 2009 \\
\hline Health promotion actions & Tobacco Control Scale Ranking & Joossens, 2013 & 2010 \\
\hline Social support & Expenditure on social protection (\% of GDP) & Eurostat & 2011 \\
\hline Social, environmental and political forces & Households with internet access (\%) & Eurostat & 2011 \\
\hline
\end{tabular}


Table 3. Cont.

\begin{tabular}{|c|c|c|c|}
\hline Sub-Area & Indicator & Data Source & Year \\
\hline \multicolumn{4}{|c|}{ Consequences } \\
\hline $\begin{array}{l}\text { Capacity to act independently on } \\
\text { knowledge, Motivation and } \\
\text { self-confidence, individual resilience, } \\
\text { Ability to apply information to novel } \\
\text { situations, Ability to participate in public } \\
\text { and private dialogues about health, } \\
\text { medicine, scientific knowledge and } \\
\text { cultural beliefs, self-efficacy, attitudes }\end{array}$ & Consumer Empowerment Index score & Eurobarometer & 2011 \\
\hline $\begin{array}{l}\text { Health knowledge (risk, diseases and } \\
\text { treatments) }\end{array}$ & Individuals (16-74) using the internet for seeking health information (\%) & Eurostat & 2011 \\
\hline Health behavior & Prevalence of overweight $(\%)$ & Health for All & 2010 \\
\hline Health behavior & Pure alcohol consumption (litres per capita) & Health for All & 2011 \\
\hline Health behavior & Adult population smoking daily (\%) & OECD & 2010 \\
\hline Health outcomes & Life expectancy at birth & Eurostat & 2011 \\
\hline Health outcomes & Suicide and self-inflicted injury death rate per 100,000 abitants & Health for All & 2011 \\
\hline Health status & Self-perceived health-\% Bad & Eurostat & 2011 \\
\hline Health outcomes & $\begin{array}{l}\text { People having a long-standing illness or health problem by educational } \\
\text { attainment level }\end{array}$ & Eurostat & 2011 \\
\hline Health outcomes & Euro Health Consumer Index-Outcomes sub-discipline & $\mathrm{HCP}$ & 2009 \\
\hline Hospitalization & Hospital discharges per 1000 inhabitants & OECD & 2010 \\
\hline Healthcare costs & Total health expenditure (\% of GDP) & Health for All & 2011 \\
\hline Healthcare costs & Private expenditure on health as $\%$ of total expenditure on health & Health for All & 2011 \\
\hline Healthcare access & Self-reported unmet need for medical examination or treatment & Eurostat & 2011 \\
\hline Screening behaviors & Mammography screening, women aged 50-69 screened (\%) & OECD & 2010 \\
\hline $\begin{array}{l}\text { Improved capacity to influence social } \\
\text { norms and interact with social groups }\end{array}$ & $\begin{array}{l}\text { Individuals using the internet for interacting with public authorities (last } 12 \\
\text { months) }(\%)\end{array}$ & Eurostat & 2011 \\
\hline Social injustice & Crime, violence or vandalism in the area & Eurostat & 2011 \\
\hline Social injustice & UNDP Human Development Index (HDI) & Health for All & 2011 \\
\hline
\end{tabular}

HCP: Health Consumer Powerhouse; OECD: Organisation for Economic Co-operation and Development; UNDP: United Nations Development Programme. 
Table 4. Spearman's correlation between HL (mean value of HLS-EU-Q47 and NVS scores), its antecedents and its consequences in the eight European countries of the HL Survey.

\begin{tabular}{|c|c|c|c|c|c|}
\hline \multirow{2}{*}{\multicolumn{2}{|c|}{ Indicators }} & \multicolumn{2}{|c|}{ HLS-EUQ 47 Score } & \multicolumn{2}{|c|}{ NVS Score } \\
\hline & & Rho & $p$ & Rho & $p$ \\
\hline \multirow{19}{*}{ Antecedents } & Women/100 men & -0.611 & 0.108 & -0.614 & 0.105 \\
\hline & Population aged $65+(\%)$ & -0.405 & 0.320 & 0.168 & 0.691 \\
\hline & Foreign-born population $(\%)$ & 0.262 & 0.531 & 0.275 & 0.509 \\
\hline & Population with post-secondary education aged $25+(\%)$ & 0.810 & 0.015 & 0.635 & 0.091 \\
\hline & $\begin{array}{l}\text { Lifelong learning-\% persons aged } 25 \text { to } 64 \text { who stated that they received education or training in the four weeks } \\
\text { preceding the survey }\end{array}$ & 0.381 & 0.352 & 0.551 & 0.157 \\
\hline & Population that use the Internet at least ones a week (\% of individuals) & 0.667 & 0.071 & 0.647 & 0.083 \\
\hline & Reading achievement (average reading performance for 15-year-old students) & 0.905 & 0.002 & 0.299 & 0.471 \\
\hline & Unemployment rate $(\%)$ & -0.071 & 0.867 & -0.778 & 0.023 \\
\hline & GDP, U.S.\$ per capita & 0.667 & 0.071 & 0.719 & 0.045 \\
\hline & Gini coefficient & -0.524 & 0.183 & -0.743 & 0.035 \\
\hline & Prevalence of chronic depression (\%) & 0.275 & 0.509 & 0.590 & 0.123 \\
\hline & Prevalence of dementia (\%) & 0.095 & 0.823 & 0.168 & 0.691 \\
\hline & National breast cancer screening program ( 0 if not, 1 if yes) & 0.732 & 0.039 & -0.113 & 0.789 \\
\hline & National cervical cancer screening program ( 0 if not, 1 if yes) & 0.873 & 0.005 & 0.274 & 0.511 \\
\hline & Hospitals per 100,000 & -0.595 & 0.120 & 0.000 & 1.000 \\
\hline & EPEI total score-rank & -0.595 & 0.120 & -0.826 & 0.011 \\
\hline & Tobacco Control Scale Ranking & -0.518 & 0.188 & 0.248 & 0.553 \\
\hline & Expenditure on social protection (\% of GDP) & 0.381 & 0.352 & 0.814 & 0.014 \\
\hline & Households with internet access (\%) & 0.286 & 0.493 & -0.036 & 0.933 \\
\hline \multirow{18}{*}{ Consequences } & Consumer Empowerment Index & 0.548 & 0.160 & 0.898 & 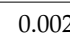 \\
\hline & Individuals (16-74) using the internet for seeking health information (\%) & 0.407 & 0.317 & 0.759 & 0.029 \\
\hline & Prevalence of overweight $(\%)$ & -0.024 & 0.955 & -0.843 & 0.009 \\
\hline & Pure alcohol consumption, litres per capita & 0.072 & 0.866 & -0.548 & 0.159 \\
\hline & Adult population smoking daily & -0.476 & 0.233 & -0.575 & 0.136 \\
\hline & Life expectancy at birth & 0.238 & 0.570 & 0.228 & 0.588 \\
\hline & Suicide and self-inflicted injury (SDR) per 100,000 & 0.048 & 0.911 & 0.060 & 0.888 \\
\hline & Self-perceived health-\% Bad & -0.595 & 0.120 & -0.275 & 0.509 \\
\hline & People having a long-standing illness or health problem by educational attainment level & 0.024 & 0.955 & -0.530 & 0.177 \\
\hline & Euro Health Consumer Index-Outcomes sub-discipline & 0.790 & 0.020 & 0.789 & 0.020 \\
\hline & Hospital discharges per 1000 inhabitants & -0.524 & 0.183 & 0.228 & 0.588 \\
\hline & Total health expenditure (\% of GDP) & 0.095 & 0.823 & 0.766 & 0.027 \\
\hline & Private expenditure on health as $\%$ of total expenditure on health & -0.455 & 0.257 & -0.602 & 0.114 \\
\hline & Self-reported unmet need for medical examination or treatment & 0.371 & 0.365 & 0.566 & 0.143 \\
\hline & Mammography screening, women aged 50-69 screened (\%) & 0.381 & 0.352 & 0.419 & 0.301 \\
\hline & Individuals using the internet for interacting with public authorities (last 12 months) (\%) & 0.548 & 0.160 & 0.755 & 0.031 \\
\hline & Crime, violence or vandalism in the area & -0.286 & 0.493 & 0.323 & 0.435 \\
\hline & UNDP Human Development Index (HDI) & 0.071 & 0.867 & 0.443 & 0.272 \\
\hline
\end{tabular}


In terms of the NVS mean score, significant correlations existed among the unemployment rate $(r=-0.778)$, the Gross Domestic Product (GDP, $r=0.719)$, the Gini coefficient $(r=-0.743)$, the rank of the Euro Patient Empowerment Index (EPEI) total score $(\mathrm{r}=-0.826)$, and the expenditure on social protection $(\mathrm{r}=0.814)$ as antecedents. Moreover, the NVS mean score was also significantly associated with the Consumer Empowerment Index $(r=0.898)$, the percentage of adults using the internet for seeking health information $(r=0.759)$, the prevalence of overweight individuals $(r=-0.843)$, the "outcomes" sub-discipline of the Euro Health Consumer Index $(r=0.789)$, the total health expenditure $(r=0.766)$, and the percentage of individuals using the internet for interacting with public authorities $(r=0.755)$ as consequences.

\section{Discussion}

This study investigates the ecological relationships between the antecedents and consequences of HL as related to macro-level factors. To the best of our knowledge, no previous ecological studies on HL have previously been published. Accordingly, comparisons with other studies are not possible. On the other hand, many studies have explored the relationships the antecedents and consequences of HL at the individual level.

According to other researchers [39-41], HL is not only an individual variable but also a social practice. It is a distributed resource (distributed HL) within an individual's social network, where health literate subjects share their HL skills to support other individuals as to how to manage their health, communicate with health professionals, and make overall decisions about their health. Batterham et al. [41] stressed the importance of a distributed HL both for individual empowerment (freedom of choices and participation in decision making) and adherence to professional medical advice. Accordingly, the study of HL as an ecological variable allows us to better understand the role of this determinant of health.

Ecological design is appropriate if researchers are interested in the effect of macro-level aspects. As such, this study could be a valid contribution in terms of the concept of HL, particularly on the level of national public health. However, this type of study is potentially susceptible to ecological fallacy which can encompass several potential biases: ecological confounding, model specification bias, and ecological bias. Nevertheless, many researchers are confident that this type of study can contribute to creating reliable causal relationships [42].

Sørensen's integrated conceptual model of HL describes its predominant antecedents and consequences, which resulted from reviewing existing HL concepts [5]. HLS-EU has contributed to a validation of the conceptual model, collecting individual data in eight countries using a comprehensive questionnaire that featured two measures of HL (HLS-EU-Q47 and NVS) and 39 items referring to antecedents and consequences outlined in the conceptual model [7]. Our research further contributes a validation of the conceptual model at the national level. In the HLS-EU-Q, the identification of the 39 items to be included in the questionnaire is the result of a literature review; in our study, the identification of the indicators to be included in the correlation analysis is the result of a literature review as well. As this is the first study which analysed HL at an ecological level, the list of indicators was selected those used in various ecological studies and were attributable to antecedents or consequences as outlined in the Sørensen conceptual model. Accordingly, this study could be described as an experiment to validate the Sørensen conceptual model of HL at an ecological level and an analysis of indicators that are applicable at the national scale. Unfortunately, data availability for the eight countries involved in the HLS-EU and which referred to the three years preceding the HLS-EU limited the possible number of indicators to be entered into the analysis.

No previous ecological studies have been published with either this level of focus on indicators or which have incorporated this many data sources. Indeed, the aim of this study was to identify novel sources of "ecological" data, combining information from international databases (Eurostat, Health for All, and OECD databases) and ad hoc surveys (HLS-EU, Eurobarometer, Eurostat, European Commission, and HCP surveys, Joossens' study). 
Significant amounts of secondary data, already collected or produced by other researchers, are available for free online; this is an excellent opportunity for research, especially for emergent ecological studies. Information provided by databases associated with international organizations can usually be easily obtained via their websites; data from ad hoc surveys are usually described in the results of the studies or can be requested directly from the researchers. Nonetheless, the use of secondary data presents several limitations that could have influenced the quality of this study. Data are neither specific to the aims of this study (fitness for use), nor controlled for quality by the Authors of this study (the Authors are not responsible for primary data). The use of numerous data sources as well as the inclusion of eight nations could have reinforced these critical quality issues.

International databases are frequently compiled from various sources; they are validated and processed in a uniform way to improve the international comparability of statistics. Quality of data is a central issue in the production of health indicators for international organizations; they have quality management policies and they constantly review both their data sources and methodologies. Statistics are checked for consistency, coherence, and comparability [43-45]; however, their quality is primarily influenced by the quality of each respective nation's statistics. Additionally, for some indicators (e.g., migration statistics), a lack of international comparability is a well-known issue [46]. Moreover, the comparability and the accuracy of data reported in the international databases is limited in some cases, owing to a variety of factors including differences in definitions and/or time periods, incomplete registration, or other variations in national data recording and/or processing. Ad hoc surveys can help to overcome the limitations of internal consistency and comparability as a shared study protocol often can be generally applied across all research units. However, even these may present limitations on results due to differing sampling procedures which influence comparability across countries. Moreover, ad hoc studies are limited in time (i.e., data are not routinely collected). On the other hand, such studies usually are innovative and experimentally tentative. Occasionally, pilot exercises to describe macro-level aspects use novel indicators to compare the same phenomena in different countries. Our research may be comparable to such studies; a tentatively novel methodology to integrate significantly different sources of both routine and innovative indicators.

The results of our study are not exhaustive nor conclusive resulting from limitations in the selection of indicators (literature review not related to ecological studies on HL, lack of data availability, some areas outlined in the Sørensen model not represented in our study) as well as in the quality and comparability of some indicators. Moreover, the study design and the low number of countries involved (eight) limited the statistical analysis and the strength of the results. For example, correlation analysis is sensitive to outliers; although Spearman's correlation is less sensitive to outliers, the low number of observations may have influenced the results [47].

Despite these limitations, some tentative conclusions may be drawn from the results. This study provides some preliminary regarding the antecedents and consequences of HL which require additional analysis.

The HLS-EUQ47 and the NVS scores showed no significant correlation and presented different results in the correlation analysis. The data analysis of the HLS-EU, conducted at the individual level, showed a significantly positive but low correlation between the HLS-EU-Q47 and the NVS scores, with a coefficient equal to 0.25 [13]. The relationship between objective and subjective HL measures has received limited attention. Few studies using multiple instruments have been conducted to date [48]. At a conceptual level, these tools measure different constructs: the Sørensen definition of HL for the HLS-EUQ47 [5], that of the U.S. Department of Health and Human Services [49] for the NVS. The NVS provides a measure of individual HL, which is the consequence of both the individual skills and the complexity of the context within which people act [50]. In contrast, the HLS-EUQ47 is a measure of public HL [51]. Since they measure different aspects of HL in different ways, it is not surprising that they led to different results in this study; however, the two measurements provided a more complete picture of HL. 
Without separating the results which emerged from the two different measurement tools, our data show that HL is related to the following antecedents on an ecological (national) level: the percentage of the population with post-secondary education ( $\mathrm{r}=0.810$ with HLS-EUQ47 score), the reading achievement $(r=0.905$ with HLS-EUQ47 score), the unemployment rate $(r=-0.778$ with NVS score), the GDP ( $r=0.719$ with NVS score), the Gini coefficient ( $r=-0.743$ with NVS score), the presence of a national breast cancer screening programme $(r=0.732$ with HLS-EUQ47 score) or of a national cervical cancer screening programme ( $\mathrm{r}=0.873$ with HLS-EUQ47 score), the national rank of the EPEI total score $(r=-0.826$ with NVS score), and the expenditure on social protection $(r=0.814$ with NVS score). Surprisingly, demographic data (indicators related to gender, age, or ethnicity distribution) showed no correlation with HL. Moreover, HL stood in correlation to the following consequences: the Consumer Empowerment Index ( $\mathrm{r}=0.898$ with NVS score); the percentage of adults using the Internet for seeking health information ( $r=0.759$ with NVS score); the prevalence of overweight $(r=-0.843$ with NVS score); the outcome sub-discipline of the Euro Health Consumer Index ( $r=0.790$ with HLS-EUQ47 score, $r=0.789$ for NVS score); the total health expenditure, as percentage of GDP ( $r=0.766$ with NVS score); and the percentage of individuals using the Internet for interacting with public authorities $(r=0.755$ with NVS score).

Accordingly, national policies devoted to promote and provide the prerequisites of health (specifically education, income, social justice, and equity), to increase health coverage (i.e., the introduction of national screening programmes), and to make healthcare systems more empowering for the patients should result in a widespread increase of HL among a nation's population. On the other hand, those policies (particularly those dedicated to increasing functional HL) should contribute to the following results: an increase in consumer empowerment, the decrease of the prevalence of overweight individuals, the increase of the health status of the population, and the increase of total health expenditure. It is important to highlight that the increase of consumer empowerment as well as the decrease of the prevalence of overweight individuals and general obesity are among the main objectives of the European Commission [52,53]. Moreover, the results suggest that, where the HL of the population is high, the Internet could be used effectively by policy makers and experts for the provision of information and services related to health and health services. It may also provide a means by which to interact with the population. In contrast, in countries where the HL of the population is low, such tactics may contribute to the digital divide [54], increasing overall inequality.

\section{Conclusions}

This study provides some preliminary considerations regarding different approaches to study HL including the potential of analyzing the ecological level of HL as well as other novel methods of analysis. It also provides a list of indicators by which one may validate the Sørensen conceptual model using secondary data. Both the methods and the results need to be analysed further; however, both will offer, when weaknesses and limits are reduced, a key method to strengthen the relationship between society and healthcare protection.

Supplementary Materials: The following are available online at http:/ /www.mdpi.com/1660-4601/15/4/798/s1, Table S1: Conceptual model of HL and indicators reported in ecological studies/reports/documents by area. Table S2: Database.

Acknowledgments: None declared. This research did not receive any specific grant from funding agencies in the public, commercial, or not-for-profit sectors.

Author Contributions: C.L.: conception and design of the study; generation, collection, assembly, analysis and interpretation of data; drafting and revision of the manuscript. F.I.: conception and design of the study; generation, collection, assembly, analysis and interpretation of data; drafting and revision of the manuscript. L.B.: conception and design of the study; generation, collection, assembly, analysis and interpretation of data; revision of the manuscript. M.D.: conception and design of the study; generation, collection, assembly, analysis and interpretation of data; revision of the manuscript. F.G.: conception of the study; revision of the manuscript. G.B.: conception and design of the study; interpretation of data; drafting and revision of the manuscript.

Conflicts of Interest: The authors declare no conflict of interest. 


\section{References}

1. Kickbusch, I.S. Health literacy: Addressing the health and education divide. Health Promot. Int. 2001, 16, 289-297. [CrossRef] [PubMed]

2. Institute of Medicine. Health Literacy: A Prescription to End Confusion; National Academy Press: Washington, DC, USA, 2004.

3. Freedman, D.A.; Bess, K.D.; Tucker, H.A.; Boyd, D.L.; Tuchman, A.M.; Wallston, K.A. Public health literacy defined. Am. J. Prev. Med. 2009, 36, 446-451. [CrossRef] [PubMed]

4. Guzys, D.; Kenny, A.; Dickson-Swift, V.; Threlkeld, G. A critical review of population health literacy assessment. BMC Public Health 2015, 15, 215. [CrossRef] [PubMed]

5. Sørensen, K.; Van den Broucke, S.; Fullam, J.; Doyle, G.; Pelikan, J.; Slonska, Z.; Brand, H.; (HLS-EU) Consortium Health Literacy Project European. Health literacy and public health: A systematic review and integration of definitions and models. BMC Public Health 2012, 12, 80. [CrossRef]

6. Sørensen, K.; Van den Broucke, S.; Pelikan, J.M.; Fullam, J.; Doyle, G.; Slonska, Z.; Kondilis, B.; Stoffels, V.; Osborne, R.H.; Brand, H.; et al. Measuring health literacy in populations: Illuminating the design and development process of the European Health Literacy Survey Questionnaire (HLS-EU-Q). BMC Public Health 2013, 13, 948. [CrossRef] [PubMed]

7. Sørensen, K.; Pelikan, J.M.; Röthlin, F.; Ganahl, K.; Slonska, Z.; Doyle, G.; Fullam, J.; Kondilis, B.; Agrafiotis, D.; Uiters, E.; et al. Health literacy in Europe: Comparative results of the European health literacy survey (HLS-EU). Eur. J. Public Health 2015, 25, 1053-1058. [CrossRef] [PubMed]

8. Bo, A.; Friis, K.; Osborne, R.H.; Maindal, H.T. National indicators of health literacy: Ability to understand health information and to engage actively with healthcare providers-A population-based survey among Danish adults. BMC Public Health 2014, 14, 1095. [CrossRef] [PubMed]

9. Mantwill, S.; Monestel-Umaña, S.; Schulz, P.J. The Relationship between Health Literacy and health disparities: A systematic review. PLoS ONE 2015, 10, e0145455. [CrossRef] [PubMed]

10. Rasu, R.S.; Bawa, W.A.; Suminski, R.; Snella, K.; Warady, B. Health Literacy impact on national healthcare utilization and expenditure. Int. J. Health Policy Manag. 2015, 4, 747-755. [CrossRef] [PubMed]

11. Van der Heide, I.; Wang, J.; Droomers, M.; Spreeuwenberg, P.; Rademakers, J.; Uiters, E. The relationship between health, education, and health literacy: Results from the Dutch Adult Literacy and Life Skills Survey. J. Health Commun. 2013, 18 (Suppl. 1), 172-184. [CrossRef] [PubMed]

12. European Commission. Study on Sound Evidence for a Better Understanding of Health Literacy in the European Union. RfS Chafea/2014/health/01 Contract No 20146201; Publications Office of the European Union: Luxembourg, 2014.

13. HLS-EU Consortium. Comparative Report on Health Literacy in Eight EU Member States. Available online: http:/ / ec.europa.eu/chafea/documents / news/Comparative_report_on_health_literacy_in_eight_ EU_member_states.pdf (accessed on 12 March 2018).

14. Nutbeam, D. Health literacy as a public health goal: A challenge for contemporary health education and communication strategies into the 21st century. Health Promot. Int. 2000, 15, 259-267. [CrossRef]

15. Weiss, B.D.; Mays, M.Z.; Martz, W.; Castro, K.M.; DeWalt, D.A.; Pignone, M.P.; Mockbee, J.; Hale, F.A. Quick assessment of literacy in primary care: The newest vital sign. Ann. Fam. Med. 2005, 3, 514-522. [CrossRef] [PubMed]

16. Rowlands, G.; Khazaezadeh, N.; Oteng-Ntim, E.; Seed, P.; Barr, S.; Weiss, B.D. Development and validation of a measure of health literacy in the UK: The newest vital sign. BMC Public Health 2013, 13, 116. [CrossRef] [PubMed]

17. Davis, S.L.; Goedel, W.C.; Emerson, J.; Guven, B.S. Punitive laws, key population size estimates, and Global AIDS Response Progress Reports: An ecological study of 154 countries. J. Int. AIDS Soc. 2017, 20, 1-8. [CrossRef] [PubMed]

18. Fernández, E.; Lugo, A.; Clancy, L.; Matsuo, K.; La Vecchia, C.; Gallus, S. Smoking dependence in 18 European countries: Hard to maintain the hardening hypothesis. Prev. Med. 2015, 81, 314-319. [CrossRef] [PubMed]

19. Sun, L.; Lee, E.; Zahra, A.; Park, J. Risk Factors of Cardiovascular Disease and Their Related Socio-Economical, Environmental and Health Behavioral Factors: Focused on Low-Middle Income Countries-A Narrative Review Article. Iran J. Public Health 2015, 44, 435-444. [PubMed] 
20. Wolf, A.; Gray, R.; Faze, S. Violence as a public health problem: An ecological study of 169 countries. Soc. Sci. Med. 2014, 104, 220-227. [CrossRef] [PubMed]

21. La Torre, G.; Mipatrini, D. Country-level correlates of e-cigarette use in the European Union. Int. J. Public Health 2016, 61, 269-275. [CrossRef] [PubMed]

22. Abela, A.G.; Fava, S. Association of incidence of type 1 diabetes with mortality from infectious disease and with antibiotic susceptibility at a country level. Acta Diabetol. 2013, 50, 859-865. [CrossRef] [PubMed]

23. The Development of a European Health Promotion Monitoring System (The EUHPID Project). Final Report to the European Commission, DG SANCO March 2004. Available online: http:/ / ec.europa.eu/health/ph_ projects/2001/monitoring/fp_monitoring_2001_frep_03_en.pdf (accessed on 12 March 2018).

24. Laut, K.G.; Gale, C.P.; Pedersen, A.B.; Fox, K.A.; Lash, T.L.; Kristensen, S.D. Persistent geographical disparities in the use of primary percutaneous coronary intervention in 120 European regions: Exploring the variation. EuroIntervention 2013, 9, 469-476. [CrossRef] [PubMed]

25. European Commission. Health Inequalities in the EU. Final Report of a Consortium. Consortium Lead: Sir Michael Marmot; European Commission Directorate-General for Health and Consumers: Brussels, Belgium, 2013.

26. European Commission. Teaching Reading in Europe: Contexts, Policies and Practices; Education, Audiovisual and Culture Executive Agency (EACEA P9 Eurydice): Brussels, Belgium, 2011.

27. TNS Opinion \& Social. Standard Eurobarometer 76. Media Use in the European Union. European Commission-Directorate-General Communication, Report 2011. Available online: http:/ / ec.europa.eu/ commfrontoffice/publicopinion/archives/eb/eb76/eb76_media_en.pdf (accessed on 12 March 2018).

28. OECD Data. Forein-Born Population. Available online: Https://data.oecd.org/migration/foreign-bornpopulation.htm (accessed on 12 March 2018).

29. Joossens, L.; Raw, M. The Tobacco Control Scale 2013 in Europe; Association of European Cancer Leagues: Brussels, Belgium, 2014.

30. Lefresne, F.; Fox, T. The diversity of European education systems. In Education in Europe: Key Figures; The French Ministry of National Education, Higher Education and Research Evaluation, Forward-planning and Performance Directorate: Paris, France, 2016.

31. European Commission-International Agency for Research on Cancer. Against Cancer. Cancer Screening in the European Union; Report on the Implementation of the Council Recommendation on Cancer Screening; European Commission: Lyon, France, 2017.

32. Health Consumer Powerhouse. The Empowerment of the European Patient. Options and Implications; HCP: Brussels, Belgium, 2009.

33. Nardo, M.; Loi, M.; Rosati, R.; Manca, A.R. The Consumer Empowerment Index; Publications Office of the European Union: Luxembourg, 2011.

34. OECD. Adults, Computers and Problem Solving: What's the Problem? OECD Publishing: Paris, France, 2015.

35. OECD. Health at a Glance: Europe 2012; OECD Publishing: Paris, France, 2012.

36. Eurostat. Internet Use in Households and by Individuals in 2011. Available online: http:/ /www.ecdl.gr/el/ presscenter/press/news/Documents/Digital_Agenda_survey.pdf (accessed on 12 March 2018).

37. United Nations Development Program. Human Development Report 2016. Human Development for Everyone; United Nations Development Programme: New York, NY, USA, 2016.

38. Cedefop. On the Way to 2020: Data for Vocational Education and Training Policies. Country Statistical Overviews-2016 Update; Cedefop Research Paper No 61; Publications Office of the European Union: Luxembourg, 2017.

39. Papen, U. Literacy, learning and health-A social practices view of health literacy. Lit. Numer. Stud. 2009, 16, 19-34. [CrossRef]

40. Edwards, M.; Wood, F.; Davies, M.; Edwards, A. “Distributed health literacy": Longitudinal qualitative analysis of the roles of health literacy mediators and social networks of people living with a long-term health condition. Health Exp. 2015, 18, 1180-1193. [CrossRef] [PubMed]

41. Batterham, R.W.; Hawkins, M.; Collins, P.A.; Buchbinder, R.; Osborne, R.H. Health literacy: Applying current concepts to improve health services and reduce health inequalities. Public Health 2016, 132, 3-12. [CrossRef] [PubMed]

42. Loney, T.; Nagelkerke, N.J. The individualistic fallacy, ecological studies and instrumental variables: A causal interpretation. Emerg. Themes Epidemiol. 2014, 11, 18. [CrossRef] [PubMed] 
43. Eurostat, European Statistical System. European Statistics Code of Practice for the National and Community Statistical Authorities. Available online: http:/ / ec.europa.eu/eurostat/documents/3859598/5921861/KS32-11-955-EN.PDF/5fa1ebc6-90bb-43fa-888f-dde032471e15 (accessed on 8 April 2018).

44. World Health Organization. European Health for All Family Databases. Available online: http:/ /www.euro. who.int/en/data-and-evidence/databases/european-health-for-all-family-of-databases-hfa-db (accessed on 8 April 2018).

45. Organization for Economic Co-Operation and Development. Quality Framework and Guidelines for OECD Statistical Activities. Available online: http://www.oecd.org/officialdocuments/ publicdisplaydocumentpdf/?cote=std/qfs(2011)1\&doclanguage=en (accessed on 8 April 2018).

46. Lemaitre, G. The Comparability of International Migration Statistics. OECD, 2005. Available online: https: / / www.oecd.org/migration/mig/36064929.pdf (accessed on 8 April 2018).

47. Hazra, A.; Gogtay, N. Biostatistics Series Module 6: Correlation and Linear Regression. Indian J. Dermatol. 2016, 61, 593-601. [CrossRef] [PubMed]

48. Kiechle, E.S.; Bailey, S.C.; Hedlund, L.A.; Viera, A.J.; Sheridan, S.L. Different Measures, Different Outcomes? A Systematic Review of Performance-Based versus Self-Reported Measures of Health Literacy and Numeracy. J. Gen. Intern. Med. 2015, 30, 1538-1546. [CrossRef] [PubMed]

49. U.S. Department of Health and Human Services. Health Communication. In Healthy People 2010, 2nd ed.; U.S. Government Printing Office: Washington, DC, USA, 2000.

50. Parker, R. Measuring health literacy: What? So what? Now what? In Measures of Health Literacy: Workshop Summary, Roundtable on Health Literacy; National Academies Press: Washington, DC, USA, 2009; pp. 91-98.

51. Pleasant, A.; Kuruvilla, S. A tales of two health literacy: public health and clinical approaches to health literacy. Health Promot. Int. 2008, 23, 152-159. [CrossRef] [PubMed]

52. European Commission. Health and Consumers. Empowerment. Available online: http://ec.europa.eu/ consumers/consumer_empowerment/index_en.htm (accessed on 12 March 2018).

53. European Commission. Strategy on Nutrition, Overweight and Obesity-Related Health Issues. Available online: https:/ / ec.europa.eu/health/nutrition_physical_activity/policy/strategy_en (accessed on 12 March 2018).

54. Bodie, G.D.; Dutta, M.J. Understanding health literacy for strategic health marketing: EHealth literacy, health disparities, and the digital divide. Health Mark. Q. 2008, 25, 175-203. [CrossRef] [PubMed]

(C) 2018 by the authors. Licensee MDPI, Basel, Switzerland. This article is an open access article distributed under the terms and conditions of the Creative Commons Attribution (CC BY) license (http://creativecommons.org/licenses/by/4.0/). 